\title{
Implicaciones culturales en la interpretación de referencias sexuales en el ámbito social
}

\author{
MOHAMED EL-MAdKOURI MAATAOUI \\ Universidad Autónoma de Madrid \\ el-madkouri@uam.es
}

Recibido: 31 de enero de 2014

Aceptado: 19 de febrero 2014

\section{RESUMEN}

El objeto de este trabajo es analizar y describir algunos aspectos de la lengua cuyo conocimiento, expresión y recepción incumbe al ámbito social y cultural, más que lo puramente formal; es decir, que en ocasiones podemos entender la totalidad de las palabras sin captar el mensaje implícito o, incluso, podemos rechazar algún tipo de construcción lingüística juzgándola rara o anómala y, por tanto, poco significativa desde nuestra perspectiva social y cultural propia, aunque la misma sea altamente significativa desde el punto de vista del emisor y de su marco social y cultural. Para poner de relieve este tipo de construcciones lingüísticas, abordaré aquellas referencias y expresiones con contenido sexual que se precisa comunicar del árabe al español en el ámbito de la interpretación en los Servicios Públicos, o en el ámbito social. Por ello, este trabajo se centrará exclusivamente en la interpretación, porque es ella, frente a la traducción, la que precisa de la presencia física y efectiva de los tres actores de la comunicación, a saber: el proveedor del servicio, el usuario del mismo y el intérprete.

Palabras clave: interpretación en los SS.PP, cultura, interpretación, sexualidad, inmigración.

\section{Cultural implications in the interpretation of sexual references in social institutions}

\begin{abstract}
The purpose of this paper is to analyze and describe certain aspects of language whose knowledge, expression and reception affect the social and cultural field rather than what's purely formal; that is to say, sometimes we may understand the words but we may not understand the implicit message or we may even dismiss some kind of linguistic constructions because they are seen as strange or anomalous and therefore not very significant from our own social and cultural perspective, even though such constructions may be highly significant from the speaker's point of view and their social and cultural context.In order to highlight this kind of linguistic constructions, I will address those references and expressions with sexual content


that required to be translated from Arabic to Spanish when interpreting on the public services context. That is why this paper will focus exclusively on interpretation, given that, unlike translation, interpretation requires the physical presence and effectiveness of the three players in communication, namely: the service provider, the user of such service and the interpreter.

Keywords: community interpreting, culture, translation, sexuality, immigration.

Sumario: Introducción 1. Las practicas discursivas. 2. La construcción del discurso. 3. El contexto sociocultural del intercambio discursivo. 3.1. Las implicaciones sociales en las prácticas discursivas. 3.2. Las implicaciones culturales en las prácticas discursivas. 3.3. El factor cognitivo. 4. Conclusión.

\section{Introducción}

La presencia física de los tres actores del intercambio comunicativo determina la manera en que se construyen e interpretan las expresiones lingüísticas. No solo se requiere, por tanto, el dominio formal de las dos lenguas en contacto por parte del intérprete, sino también el dominio de aquellas reglas sociales y culturales que determinan por qué se construyen las expresiones lingüísticas en la forma en que aparecen y cómo han de interpretarse. En este aspecto, nos encontramos ante un caso no solo de asimetrías lingüísticas, sino también de asimetrías sociales y culturales. No se trata, pues, de establecer una serie de prevalencias sociales y culturales, sino de describir y explicar el porqué de este determinismo social y cultural -en el caso en que lo fuera- de las expresiones lingüísticas.

Se parte de la premisa de que las producciones lingüísticas son difícilmente disociables de su contexto social y cultural de partida, especialmente en el ámbito de la interpretación social. Es precisamente este contexto -el de la interpretación socialen el que se determina lo decible de lo no decible más allá de los formalismos puramente lingüísticos. De hecho, es la cultura la que moldea, determina y justifica las expresiones lingüísticas en torno al cuerpo humano y a la sexualidad. En este sentido, se parte de otra premisa consistente en que los sentimientos son universales (amor, odio, rivalidad...) pero que son las reglas culturales las que determinan dónde, cuándo y cómo deben expresarse; es decir, que el sentimiento podría ser uno, pero sus expresiones múltiples. Por eso, la interpretación en el ámbito social refleja ciertas dificultades cuando se ponen en contacto dos marcos culturales en los cuales el cuerpo, la intimidad y los espacios se interpretan de distintos modos.

La conceptualización tanto del espacio público como del espacio privado, de lo que se puede expresar -mediante cualquier tipo de lenguaje- en el espacio común y lo que hay que expresar en el espacio íntimo influye, sin lugar a dudas, en la construcción y recepción de las expresiones lingüísticas y en su interpretación interlingüística. Queda claro, por tanto, que no nos vamos a ocupar en este artículo de los aspectos fonéticos y gramaticales de la lengua, sino de sus usos y prácticas. Para el intérprete, la lengua es, ante todo, uso. 


\section{Las prácticas discursivas}

El intérprete -más allá de las cabinas insonorizadas y de la interpretación consecutiva en salas de reuniones cómodamente acondicionadas-desarrolla su labor en situaciones comunicativas que necesitan más competencias que el mero dominio de las dos lenguas en contacto. De hecho, el dominio de las segundas y terceras lenguas adquiridas por el intérprete durante su largo periodo formativo se ha hecho -excepto raros casos- de forma reglada. Esto quiere decir que el proceso de enseñanzaaprendizaje de estas lenguas se ha realizado sobre la base de unas lenguas estandarizadas, neutralizadas y prototípicas, pues lo que se enseña y aprende es el prototipo de la lengua con una práctica estandarizada, común a todas las zonas de su mapa de realización tanto geográfica como social. Es igualmente neutralizada porque se liman las diferencias entre sus distintas variedades. Es neutra desde el punto de vista fonético porque se presenta como un modelo prototípico a seguir por los nuevos aprendices. En estas prácticas lingüísticas, realizadas en su parte oral por locutores profesionales y mediante grabaciones mejoradas en los laboratorios, desaparece todo lo que nos podríamos encontrar en la lengua viva, practicada por personas procedentes de varias zonas del mundo y con dicciones y prácticas discursivas distintas que, a veces, comprometen la intercomprensión entre los que se suponen hablantes primarios de la misma lengua.

Se han dado casos reales de intérpretes españoles al inglés que tuvieron problemas en entenderse con hablantes procedentes de otros países de habla española en el aeropuerto de Sidney, por ejemplo. Se trata, en este caso concreto, de una intérprete que no pudo hacerse entender con un solicitante de asilo político hispano en los primeros minutos del intercambio discursivo, lo que hizo sospechar al policía australiano si dicho solicitante era realmente cubano y si lo que decía hablar era verdaderamente español. Era lógico que el agente -vistos los desencuentros inicialespensara que si la intérprete es española y el solicitante pidiera un intérprete de dicha lengua, lo normal es que se entendieran. Si no lo han hecho, es que esa persona solicitante de asilo - pensaría el agente de la autoridad- ha querido hacerse pasar por cubana.

Este ejemplo es bastante revelador de lo que ocurre con frecuencia en el ámbito de la interpretación en los Servicios Públicos. Nuestro oído, acostumbrado a la dicción de los locutores bien entrenados de la BBC, CNN, Radio France International o de Al-Jazeera, nos juega una mala pasada cuando la persona a quien tenemos que interpretar es de Nigeria, Costa de Marfil o de Sudán del Sur. Sin embargo, aunque estos contratiempos fonéticos y léxicos son, por lo general, superables con la práctica y el tiempo de "exposición" a estas realizaciones y prácticas juzgadas inicialmente anómalas, raras..., existen otros aspectos de las prácticas discursivas cuya superación pervive en el tiempo. El acento, la prosodia y el léxico que se nos antojan extraños al principio pierden sus particularidades distintivas con la práctica. Es como si un intérprete madrileño se fuera durante dos semanas al campo de Extremadura para mediar entre agricultores del campo profundo e investigadores angloparlantes de las higueras extremeñas. Al principio, pueden extrañar el acento, la prosodia, el léxico y los giros, pero esto va neutralizándose poco a poco. Hasta puede, 
pasados los días, contestar a los agricultores, si se empeña, en su propio sociolecto, una vez que haya pasado por la síntesis de las reglas fonéticas del uso, tanto de esa variedad diatópica como dentro de ella, de la diastrática.

No obstante, esto es difícilmente superable cuando las reglas de uso de la lengua son externas al sistema lingüístico, pues, desde el punto de vista estrictamente lingüístico, uno habla correctamente una lengua si domina el uso de sus normas léxicas y gramaticales. Sin embargo, existe otra dimensión del hablar bien o hablar correctamente cuyas reglas son difusas y proceden de las normas sociales y culturales de las prácticas discursivas. Estas normas -que no aparecen en los manualesson las que regulan qué decir y qué callar y, sobre todo, cómo decirlo. Si bien es verdad que, como afirmaba Roman Jakobson (1959), todo lo que puede decirse en una lengua podría decirse en otra, las normas culturales ponen coto a las posibilidades del decir y regulan las posibilidades de la verbalización y comunicación del pensamiento de los sujetos hablantes. Las reglas sociales y culturales se imponen a las prácticas discursivas como en el caso de los tabúes, por ejemplo.

El tabú es principalmente de dos tipos: 1) positivo, cuando algo está tan lleno de fuerza espiritual que hay que cuidar de no aproximarse demasiado a ello (por ejemplo, el tabú del arca de la alianza); y 2) negativo, cuando algo está contaminado y por tanto no debe tocarse (Nida y Taber 1974 :115).

De ahí que el tema de los tabúes discursivos sea determinante para la comprensión del discurso en algunos de los ámbitos de la interpretación en los Servicios Públicos. No obstante, cabe señalar aquí un dato que consideramos muy determinante de la comunicación de los temas sexuales entre el árabe y el español. El tema del sexo no es tabú en sí (ni es positivo, ni es negativo desde el punto de vista de las prácticas discursivas entre iguales), pero sí lo son algunas construcciones lingüísticas que lo denotan públicamente; es decir, que se puede hablar abiertamente del sexo, pero sabiendo cuándo, dónde y con quién.

El espacio, el tiempo y el destinatario determinan el discurso árabe tradicional sobre el sexo. Sin embargo, para que quede claro desde el principio, en lo referente a las culturas árabes, es la cultura la que pone las reglas a las prácticas discursivas sobre el sexo y no la religión, como podría suponerse a primera vista. De hecho, el discurso teológico musulmán es más abierto, cuando se trata de educación sexual, que el discurso común diario.

Un imán, teólogo musulmán, puede abordar este tema desde el púlpito y ante hombres y mujeres de diferentes edades, pero esto no suele ocurrir en otros tipos de discursos, a menos que sea en las aulas de clase, y no de todos los países árabes. Este fenómeno se parece (en su antagonismo religión-cultura) a la separación espacial entre hombres y mujeres en algunos países musulmanes. En el recinto que se supone el centro sagrado de los musulmanes, hombres y mujeres se codean, van dando vueltas a la Kaaba y rezan cuando toca cada uno en su sitio, sin separación alguna. Además, hasta las propias saudíes ataviadas tradicionalmente con el niqab que cubre totalmente la cara, tienen que destaparla cuando entran a dicho recinto. No obstante, una vez terminadas estas vueltas y ya en el espacio profano, tienen que rezar 
separados, y las mujeres del Golfo Pérsico deben hacerlo, generalmente, cubiertas. No es una cuestión, por tanto, de religión, sino de tradición.

Del mismo modo, cuando en un sermón religioso musulmán se escucha "no hay rubor en materia de fe", esto supone que lo que sigue versará sobre relaciones carnales y de pareja en términos generales, y puede ser también una invitación a que el creyente pregunte sobre estos temas. Abundan las muestras de este tipo de discurso en internet, incluso en sistemas teológicos como el iraní. En este vídeo en persa, subtitulado en árabe (http://www.youtube.com/watch?v=8wXDtRyBp54 - 18.09.2013), el profesor es explícito sobre tocamientos, preservativos, felaciones y la ingesta del semen porque "su sabor no es desagradable". Por ello, nada impide, desde el punto de vista religioso, que una mujer explique sus dolencias ginecológicas al médico. Es la cultura la que pone las reglas, y son iguales, generalmente, tanto para los cristianos árabes como para los musulmanes. Incluso son más conservadoras, en ocasiones, las comunidades cristianas árabes - por ser características de las minorías- que las musulmanas en países como Jordania, Palestina e Irak, por ejemplo.

\section{La construcción del discurso}

La base lingüística en la construcción del discurso es ineludible. Aunque la palabra cultura y todo su campo léxico-semántico es demasiado reiterado en la actualidad, cuando se habla de la construcción y de la recepción de los discursos, especialmente en traducción e interpretación, la base lingüística de dicha construcción no puede obviarse ni despreciarse. Las bases lingüística y cultural del discurso no son contradictorias ni opuestas, sino complementarias, tanto en la parte de la comprensión del discurso que hay que traducir o interpretar, como en la de la expresión de nuestro discurso como traductores e intérpretes.

Lengua y cultura pertenecen a dos fases en el tratamiento de la traducción y de la interpretación y su traductología desde hace treinta años. De hecho, la consideración estrictamente lingüística sobresalía en los años setenta y ochenta del siglo XX, mientras que la consideración cultural es actual. Definiciones como la siguiente eran las más comunes en esa época (La Grande Encyclopédie, 1976):

La traduction est un cas particulier de convergence linguistique: au sens le plus large, elle désigne toute forme de "médiation interlinguistique", permettant de transmettre de l'information entre locuteurs de langues différentes. La traduction fait passer un message d'une langue de départ (LD) ou langue-source, dans une langue d'arrivée (LA), ou langue-cible. [La traducción es un caso particular de convergencia lingüística: en el sentido más amplio posible, hace referencia a cualquier forma de "mediación interlingüística", permitiendo transmitir informaciones entre locutores de lenguas distintas. La traducción lleva un mensaje de una lengua de salida (LS), o lengua-fuente, a una lengua de llegada (LL), o lengua-diana).

Podría afirmarse, por tanto, que en la actualidad, el campo léxico-semántico de cultura, cultural, intercultural, transcultural, cognitivo, cognitivista... ha venido 
a suplantar el de lingüistica, interlingüistica... Si la cita anterior fuera actual, diríamos, seguramente, mediación intercultural en vez de interlingüistica. Sin embargo, este cambio de perspectiva tiene su legitimidad y lógica histórica teniendo en cuenta que la comprensión del fenómeno lingüístico y de sus circunstancias es progresiva.

Desde que la lingüística ha pasado de ser exclusivamente oracional (lingüística estructuralista, funcionalista y generativista) a la consideración supraoracional en los análisis lingüísticos (lingüística del texto, pragmática y lingüística cognitiva), se ha hecho evidente que lo "exclusivamente lingüístico" no lo es todo en traducción e interpretación, sino solo una de las partes, aunque fundamental, de la comprensión y expresión en el proceso de esta actividad. Podemos, por ello, afirmar desde el ámbito de la interpretación en los Servicios Públicos, siguiendo a Íñiguez Rueda (2009, 109), que:

Un discurso es un conjunto de prácticas lingüísticas que mantienen y promueven ciertas relaciones sociales. El análisis consiste en estudiar cómo estas prácticas actúan en el presente manteniendo y promoviendo estas relaciones: es sacar a la luz el poder del lenguaje como una práctica constituyente y regulativa.

Las implicaciones discursivas del discurso y el peso de las sociedades con sus reglas dimanantes de sus valores ideológicos y culturales son igual de fundamentales. E incluso más cuando se trata de la interpretación en los Servicios Públicos.

\section{El contexto sociocultural del intercambio discursivo}

Queda claro que las prácticas lingüísticas y discursivas en la labor del intérprete en los Servicios Públicos se efectúan en un contexto concreto, con unos hablantes y oyentes específicos que realizan sus producciones lingüísticas de la manera en que las realizan socialmente y de un modo en que su cultura determina como natural. Un nigeriano o un chadiano se expresan en inglés y francés, respectivamente, con la naturalidad de quien habla su propia lengua. Sin embargo, la forma natural y espontánea de estos hablantes particulares le podría resultar anómala en un principio al intérprete del endogrupo por cuanto supone una desviación con respecto a las lenguas que adquirió de forma reglada (El-Madkouri y Soto Aranda: 2012).

Esta desviación puede llegar en ocasiones - y no es raro- a comprometer la labor de intercomprensión que teóricamente debe garantizar dicho intérprete. En este sentido, no solo el acento, sino también el léxico y algunos fraseologismos le pueden resultar extraños al intérprete autóctono (El-Madkouri y Soto Aranda: 2012). De hecho, muchos exclaman, en su primer contacto con estos hablantes, que "no se les entiende", "hablan raro". Si el intérprete es europeo y el hablante africano, la culpa de la falta de comprensión de esas variantes del inglés y del francés es de los africanos. Es como si el intérprete se esperara que estas personas reprodujeran las expresiones lingüísticas de los locutores profesionales con los cuales se ha acostumbrado a aprender inglés o francés. La tarea de asegurar una comunicación flui- 
da es aún más complicada por las transferencias sociales y culturales de la cultura y lengua originales.

\subsection{Las implicaciones sociales en las prácticas discursivas}

Más determinantes aún para el éxito de la comunicación en los Servicios Públicos son las constricciones y condicionamientos de índole social. El hecho de que en español, por ejemplo, se explicite el femenino en el discurso, a pesar de que el género masculino es incluyente del mismo, es una regla social y no gramatical. Es este tipo de reglas sociales el que obliga a construir expresiones de tipo:

•-“Estimad@amig@”.

- -O la famosa expresión ministerial de "miembras de...", por "miembros de...". - -"La elección de la presidencia de la Asociación", en vez de "la elección del presidente de la Asociación".

En este tipo de reglas existe un fuerte componente ideológico, no siempre homologable desde el punto de vista sociolingüístico, aunque la lengua de comunicación sea una de las lenguas aprendidas de forma reglada: inglés, francés, árabe... Tal es el caso de algunos países africanos de habla inglesa o francesa como Nigeria o Camerún, por ejemplo. Aquí no se trata solo la palpable variedad lingüística y sus rasgos diferenciales con las lenguas de la metrópoli, sino que en el proceso de construcción de enunciados, orales o escritos, el emisor parte de un cúmulo de informaciones conscientes y subconscientes distintas de unas comunidades de habla a otras de la misma lengua. Si a esto se añade el hecho de que en el polo opuesto, el receptor no parte necesariamente de los mismos presupuestos sociolectales e ideológicos, se puede entender cómo el traductor y el intérprete necesitan un conocimiento que transciende el mero dominio de los formalismos lingüísticos de la lengua de la metrópoli.

Estas variedades lingüísticas y variaciones discursivas son las causas del fracaso comunicativo cuando el intérprete no está familiarizado con ellas o intenta aplicar sus patrones interpretativos a otras prácticas lingüísticas. Esto es, que el intérprete puede entender los presupuestos lingüísticos de su cliente, pero no tanto sus objetivos comunicativos; es decir, que puede descifrar, en el mejor de los casos, el decir, pero no sabrá detectar -a no ser que sea experimentado- el querer decir.

El pudor, por ejemplo, obliga en este caso a decir algo haciendo referencia a otras informaciones y contenidos no explícitos en el enunciado. El intérprete, en sus primeros tanteos, oscilará en este caso concreto entre la incomprensión y el malentendido. La incomprensión (simbolizada por la famosa expresión de "ino se le entiende!") se origina cuando el receptor no entiende nada o solo entiende una parte de un enunciado construido "atípicamente" por causa del pudor. El intérprete -dependiendo de su propia seguridad y de la solidez de sus conocimientos y destrezas- reaccionará de dos modos: “iNo se le entiende!”, culpabilizando del fracaso a su cliente, o volviendo a preguntar -en el supuesto de que el enunciado pudiera estar 
construido sobre posibles postulados culturales- y dudando de que algo falla o falta para que pueda entender cabalmente lo que acaba de escuchar.

La característica principal de esta actitud es que el intérprete sabe que algo falla en su comprensión. Un ejemplo sería cuando el intérprete trivializa la realidad comunicativa pensando que el fallo es achacable a su interlocutor. Por el contrario, el malentendido se produce cuando el receptor interpreta el discurso de una manera distinta a lo que el emisor quiere expresar. Aunque la falta de comprensión es perjudicial a los intereses del inmigrante en la interpretación en los Servicios Públicos, el malentendido es aún peor porque se le hace decir al inmigrante o solicitante de asilo lo que no ha pretendido ni ha pensado. El intérprete en ningún caso se da cuenta de que se ha interpretado mal, y el proveedor del servicio (agente de la autoridad) decide sobre datos erróneos o puede llegar, a veces, a achacar mala fe al usuario. Esto ocurre normalmente no solo en árabe, donde el marco cultural determina el eufemismo y el simbolismo, sino también en el francés de muchos senegaleses.

Cabe destacar que estos eufemismos y sus correspondientes malentendidos no se dan solo entre culturas distintas (árabe-español), sino que se pueden originar también en el seno de una misma cultura. En ese sentido, el árabe magrebí, sin ser tan explícito como el español, por ejemplo, lo es más que la lengua árabe hablada por ciudadanos del Golfo Pérsico o Libia, entre otros. Estas diferencias culturales son importantes a la hora de traducir, pero muy determinantes a la hora de interpretar. La inmediatez y la presencia física del productor de enunciados determinan los eufemismos y los giros simbólicos en la interpretación. Sin embargo, en la traducción, el mismo hablante puede elaborar escritos más o menos explícitos. En este sentido, se puede afirmar que las variedades y variaciones lingüísticas alejadas de las realizaciones sociolectales de la metrópoli, en el caso del inglés y del francés, o con otras prácticas sociolingüísticas, como en el caso del mundo árabe, determinan el éxito o fracaso de la labor del intérprete en los Servicios Públicos.

\subsection{Las implicaciones culturales en las prácticas discursivas}

Partiendo de la premisa de que cuando hablamos o escribimos no lo hacemos solo a título individual, sino también social y cultural, podemos suponer cuánto son determinantes los factores sociales y culturales en el aspecto final de los constructos lingüísticos. Sin darnos cuenta, la sociedad y la cultura hablan y escriben por nuestra boca y con nuestros dedos porque "el discurso es el lenguaje en tanto que práctica social determinada por estructuras sociales" (Íñiguez Rueda, 2009, 109). Además, determinan lo que debemos decir y lo que debemos callar (Torruella Valverde, 2013):

- Entonces, ¿usted nunca interpretaría, por ejemplo, el proceso para realizar una toma de muestra de semen?

- No, nunca. Yo nunca le podría pedir eso o traducirle eso a un hombre musulmán.

- ¿Y si fuera un árabe, pero cristiano?

- Mmm...no, porque es de la misma cultura. ¿Ves?, a un saharaui [subsahariano] si que se lo diría porque no es de la misma cultura, pero a un egipcio, arge- 
lino, jordano... ni hablar. Son cosas que una mujer no le preguntaría nunca a un hombre.

Solo así podemos entender, en discursos más elaborados, por qué los escritos literarios y lúdicos se consideran también como documentos sociológicos y culturales (históricos). El texto de un escritor, por ejemplo, informa de su sociedad y cultura, pero también a través del conocimiento de estos factores sociales y culturales (vida y obra de una determinada persona) podemos entender y explicar sus escritos.

\subsection{El factor cognitivo}

La cognición es un factor determinante tanto de la construcción de las unidades lingüísticas como de su procesamiento. De hecho, cuando hablamos -más allá de las reglas gramaticales y léxicas puramente lingüísticas-, lo hacemos siguiendo patrones preestablecidos. Esto es, hablamos como se habla y como se debe hablar, siguiendo intuitivamente unas reglas subliminales que hemos ido adquiriendo durante el proceso del aprendizaje de la lengua y su uso. A todos nos viene a la cabeza la imagen de los padres que recriminan con más o menos amabilidad a su hijito en el carrito de bebés cuando este no da las "gracias" ante un regalito o un piropo; es decir, que no solo adquirimos la lengua, sino las reglas de su uso. Debemos saber en cada momento qué expresiones usar y cuáles evitar.

En el tema del pudor y del tabú, pensamos una cosa y decimos otra o expresamos la misma realidad de una forma en un contexto y de otra en otro..., así que la diferencia entre "culo" y "trasero" es, además de registro, contextual. Y así todo el léxico relacionado con el aparato reproductor. Ahora bien, algunas culturas han restringido este campo semántico-léxico a lo mínimo, arrojando al lenguaje común lo que antes era indecible. Así, en español, "pene" y "vagina" no producen ningún reparo en su mención en una consulta médica, incluso en reuniones de amigos (en vez de los antiguos "aparato sexual masculino o femenino"), sin embargo, estas palabras causan cierto reparo en otros marcos culturales como el árabe, por ejemplo (Torruella Valverde, 2013):

Bueno, las partes sexuales pues se dicen diferente... Por ejemplo, la "vagina" se dice "parte baja" o "lugar de la orina", /mantiqat al-bwl/...; del hombre se dice /al-"udw al-dhakry/, "miembro masculino"... Bueno, en argelino se dice así, otros árabes no sé. Igual con el ano (aquí la mujer lo dice en voz baja) que yo digo /mantiqat al-biraz/, "lugar de las heces".

A veces, en contextos determinados se manifiesta cierto reparo en la mención ante un público desconocido no solo de estas palabras, sino de otras como "embarazo" o incluso "casamiento".

En este caso podemos decir que las reglas para la producción de estas palabras, o para su omisión o sustitución, pertenecen al mundo de la cognición lingüística y cultural. Es esta misma cognición diferencial la que controla tanto las reglas de uso 
como de procesamiento de este tipo de reglas. En este sentido, podemos afirmar que el marco para el discernimiento de lo decible y de lo indecible pertenece a la esfera social y cultural, y que su conocimiento es cognitivo. Ahora bien, en la interpretación en los Servicios Públicos se dan muy a menudo malentendidos cuando se comparten o se ignoran los códigos culturales de la producción y recepción de los discursos "atípicos". De hecho, lo que se dice y lo que se entiende puede diferir incluso en la misma lengua y compartiendo los mismos códigos culturales. Sirva de ejemplo esta afirmación de Juan Cercas (2003: 8) que, aunque pensada para la entrevista literaria, puede generalizarse para cualquier tipo de entrevista:

El de la entrevista es género literario raro. Algunas personas que han padecido demasiadas tienden a pensar que, cuando se lee una de ellas, casi nunca se lee lo que ha dicho el entrevistado, sino lo que ha entendido el entrevistador, lo que es muy distinto...

Esta diferencia entre lo que se dice y lo que se entiende es muy común en la interpretación en los Servicios Públicos, máxime cuando el mismo hablante interpretado dice algo queriendo decir otra cosa; es decir, que el mismo hablante, en este caso inmigrante, elude nombrar la realidad como se nombra en el marco lingüístico-cognitivo, dejando al intérprete la responsabilidad de restituir su querer decir.

\subsection{El marco organizativo de las prácticas discursivas}

La organización de las prácticas discursivas en las cuales está implicada una tercera persona (intérprete) entre el emisor y el receptor es particular, pues se dan generalmente estas combinaciones:

El intérprete es parte del endogrupo

En este caso, tanto el representante de las instituciones públicas y no públicas como el intérprete comparten los mismos códigos culturales y lingüísticos, pero no con el inmigrante. En esta cuestión, cuando se trata del pudor y de los tabúes, el usuario del servicio, inmigrante, puede explicitar todo aquello que a un intérprete de su grupo de referencia no diría. Al no compartir los mismos códigos culturales con el intérprete, el inmigrante puede, en ocasiones, ser más explícito porque su intérprete "no sabe", es decir, que este no sabe qué es lo que se puede decir y lo que no.

Cabe destacar también el factor determinante del sexo. Si las tres personas son del mismo sexo, la comunicación será más fluida que si el miembro del exogrupo es de un sexo distinto al de los dos miembros del endogrupo. Menos complicado todavía si una de las dos personas del endogrupo es del sexo de la del exogrupo, pues se siente acompañada por la otra mujer. De hecho, las mujeres árabes prefieren, en general, ser tratadas por personas de su mismo sexo. Por ello, algunas profesionales hacen negocio con este hecho cultural, como refleja esta dentista alemana afincada 
en Dubai (Airberlin Magazin 12/2013 : 14): “Arab women set great store by being traeted by a member of their own sex". Estos factores extralingüísticos son determinantes para el éxito o el fracaso de la comunicación. Si una mujer viene a denunciar una violación o a que le realicen una exploración ginecológica, se sentirá más a gusto si al menos la persona que realiza la interpretación es una mujer. Aun así, siempre hay algo que no expresa explícitamente.

El intérprete es parte del exogrupo

Si el intérprete está formado como tal y domina las lenguas de contacto, esta es la situación ideal, siempre que no concurran las siguientes situaciones:

Intérprete masculino, usuario femenino

Si la información que se quiere comunicar es estimada por la usuaria como íntima y cae bajo aquello que ella no puede expresar con espontaneidad, manifiesta, generalmente, dos actitudes: en el primer caso, se niega a hablar. O lo hace, pero transmitiendo la mínima información posible. En el segundo, se presenta comunicativa, pero lo hace en un nivel simbólico, lo que obliga al intérprete a reinterpretarlo todo haciendo uso de sus conocimientos cognitivos para desenmascarar su querer decir.

Intérprete femenino, usuario masculino

Por la experiencia acumulada durante nuestra coordinación del Servicio de Traductores e Intérpretes de Comrade, se dan las mismas circunstancias que en el caso anterior $\mathrm{y}$, a veces, incluso más. Al hombre árabe le va a costar más expresarse sobre su intimidad si hay una mujer de su propia cultura que si no la hay. La situación se hace, a veces, intensa y artificial, algo que, en ocasiones, incomoda al proveedor del servicio, sobre todo si es miembro de las fuerzas de seguridad, porque no controla del todo la situación, no sabe el porqué de la tensión e incomodidad tanto del usuario del servicio como de la intérprete, llegando a veces a sospechar que se le está ocultando información. Peor todavía para el hombre árabe si las otras dos personas implicadas en el acto comunicativo son de sexo femenino. Aquí las respuestas del usuario son lacónicas y siempre mucho más breves que las producciones lingüísticas de la intérprete, que, se supone, calcan lo dicho. Es muy frecuente escuchar del representante de la Autoridad:

- Si no ha hablado tanto!

- iEs que le da corte decirlo todo!

- ¡Y Vd. le complementa, claro! 
Estas prácticas discursivas entre el usuario del Servicio Público, el proveedor del servicio y el intérprete se han puesto de relieve en los últimos cinco años, dado que estos conocimientos no han calado todavía en los servicios de la administración pública. Estas situaciones son a veces incómodas. La intérprete, miembro del exogrupo, también manifiesta cierto reparo a la hora de nombrar los órganos genitales, no solo su cliente (Torruella Valverde, 2013):

Pues soy directa. Para "vagina", directamente señalo, porque me parece algo vulgar llamarlo por su nombre. Sé que hay mediadoras que lo traducen como /mantiqat al-bwl/, pero claro, eso también puede servir para "pene", porque es por donde sale el pipí. Para los hombres les digo /dialek/, que en dialecto marroquí es algo así como "el tuyo", y si hace falta también señalo con más discreción. Y para ano, pues como aquí decimos, ¿no?, "parte trasera", que sería /wara'.

Cabe señalar igualmente que, en ocasiones, el intérprete perteneciente al exogrupo se siente superior al usuario de sus mismas referencias culturales y responsable de sus posibles fallos comunicativos; es decir, que el intérprete siente comprometer su propia imagen por parte de un usuario del servicio, que percibe como inculto, atrasado, etc. El intérprete puede llegar, en estas ocasiones, a manifestar por activa (verbalmente) o por pasiva (mímica, mirada, soplos) su animadversión con una persona con quien se supone que comparte los mismos códigos lingüísticos. El intérprete se presenta aquí como educador (Torruella Valverde, 2013):

Porque la cultura de aquí es una cultura donde se da mucha importancia a la transparencia, a la información como derecho y, por otro lado, se le da importancia a la voluntad de la persona interesada. Eso no es habitual en algunos países árabes. Para ellos es como decir: "vale, en casos normales a mí no me suelen hablar de consecuencias negativas ni me piden el consentimiento para operarme, entonces, si me lo piden y me lo dicen, quiere decir que lo que hay es grave". Se alarman tanto que hubo dos casos que se pararon en seco cuando todo estaba ya preparado para la operación... analíticas, ecografías... la sala, la habitación, todo reservado.

En todo caso, este tipo de comunicación no verbal no solo tiene lugar entre el usuario del servicio y el intérprete, sino también en todo el proceso comunicativo en los Servicios Públicos. En este sentido, y en el ámbito de la interpretación en los Servicios Públicos, Corsellis (2008: 128-142) afirma, en su traducción española (Valero y Cobás, 2010: 121-153), que:

Desde el punto de vista sociocultural, un componente importante para que la comunicación tenga éxito es la comunicación no verbal, en especial la visual: expresiones faciales y gestos (kinesia), la comunicación táctil, como el contacto corporal y la distancia entre los interlocutores (proxémica). Saber leer las "señales" es una habilidad altamente desarrollada entre los mejores profesionales de los Servicios Públicos que tienen un conocimiento intuitivo de las pistas no verbales dentro de su propia cultura.

De hecho, estas señales también son comunicativas y transmiten mucha información por vías no verbales. Por ello, la construcción y difusión del conocimien- 
to sobre estos hechos comunicativos por y entre los miembros de la comunidad investigadora significa poner de relieve las convenciones y normas que rigen las prácticas discursivas características de la interacción verbal de contenido íntimo o juzgado como "pudoroso". Se precisa por ende, seguir describiendo la estructura organizativa del discurso púdico - desde varias lenguas y marcos culturales-sobre la base de la detección de las implicaciones cognitivas que relacionan el conocimiento cultural y social con la comunicación, con el objeto de situar la investigación sobre los tabúes en la interpretación en los Servicios Públicos en un marco conceptual correcto.

\section{Lo previsible y lo imprevisible}

Otro de los factores observables en la interpretación del contenido púdico en el ámbito social es la imprevisibilidad. No todo es previsible, ni todos los usuarios son cortados por el mismo patrón. Es verdad que la cultura es determinante de muchas prácticas lingüísticas, pero no fabrica sujetos hablantes en serie. La cultura no es una fábrica que produce los mismos prototipos de hablantes "ruborizados" y "ruborizadas". En este sentido, la cultura tiene mucho que ver con la configuración de las expresiones lingüísticas, pero el hablante puede alterar $-\mathrm{y}$ de hecho lo hace en varias ocasiones- el orden previsible y evade "el determinismo cultural" que a veces se le impone. Podemos encontrarnos, y de hecho nos hemos encontrado, con personas que en vez de ruborizarse, "ruborizan" al intérprete.

\section{La afirmación y la negación}

La afirmación y la negación es un tema que hay que tomar muy en serio en la interpretación en los Servicios Públicos, especialmente en los ámbitos judicial y médico. En árabe no se niega del mismo modo que en español. Si pregunto "¿no vienes?", en caso de que la afirmación sea negativa (que no viene) un hablante español diría "no". Con ello niega no la proposición lingüística, sino el hecho real de no venir. Es decir, que lo confirma: "no, no vengo". Mientras que un árabe diría: "sí", es decir, sí a la proposición "¿no vienes?"; el hablante valida el contenido semántico de la proposición lingüística. Es decir: "sí, no vengo".

Ahora bien, los dialectos árabes son ambiguos a este respecto y funcionan tanto como el prototipo del árabe clásico como el del español. Por lo que el intérprete ha de evaluar con cada hablante si afirma o niega cuando la pregunta se plantea como una negación.

\section{Los factores paralingüísticos}

Otro aspecto a tener en cuenta es el aspecto quinésico, a saber: la mímica, la sonrisa o risa, la gesticulación o el contacto ocular (Torruella Valverde, 2013). Además, 
en ocasiones, este lenguaje transmite una información que puede contradecir o aparentar contradecir lo dicho verbalmente, como lo que revela este intérprete:

- Explique una experiencia, anécdota o algo que le haya sorprendido y que haya vivido como intérprete-mediador/a del ámbito jurídico-judicial, donde los protagonistas sean profesionales occidentales y usuarios árabes o viceversa.

- Pues un caso que me pasó y que me llevó a romperme la cabeza hasta que no consegui entender lo que el hombre decía... Es que vino un chico pidiendo el asilo y al preguntarle “¿cuántos hermanos tienes?” empezó a contar con los dedos: uno, dos, tres, cuatro... Y así se estuvo un rato. Tú veías que iba contando y descontando, y que utilizaba las dos manos. Al final dijo "dos". Claro, imagina, está contando un montón de rato con las dos manos y al final solo dice que tiene dos hermanos, eso lleva a desconfiar de si dice la verdad. Pero sí, la decía, porque al parecer, su padre se había casado dos o tres veces, y su madre también, así que tenía hermanos por ambas partes, pero él creía que en Occidente solo son válidos los hermanos que se tienen de padre y madre... Así que de padre y madre solo tenía dos.

Es verdad que la quinésica tiene su propio código. Aunque muchas veces ayuda a descifrar los enunciados verbales, otras complica la comunicación, como en el ejemplo anteriormente citado. Ahora bien, la quinésica es muy usada en la cultura árabe para no verbalizar algunos contenidos que se juzgan inapropiados para algunas situaciones comunicativas. Téngase en cuenta que muchas mujeres árabes se llevan de intérpretes a sus propios hijos menores, y cuando el tema de la consulta o alguna de las preguntas del personal sanitario, por ejemplo, versa sobre relaciones sexuales y sus consecuencias, la hablante se inhibe intentando usar disimuladamente el lenguaje quinésico. En estos casos, la comunicación se altera por no operar los dos polos del intercambio informativo con el mismo código interpretativo de la comunicación no verbal. Estas dificultades se dan igualmente cuando el intérprete es miembro del endogrupo.

\section{El factor ideológico}

El factor ideológico es determinante, en algunos casos, de las interacciones comunicativas en el ámbito de la interpretación en los Servicios Públicos.

Toda interpretación, cada ideología, es un intento de imponer una pauta -alguna forma de estructura u organización- sobre cómo leemos (y malinterpretamos) los sucesos, acontecimientos, acciones o hechos políticos; sobre cómo vemos las imágenes o escuchamos las palabras. Los mapas ideológicos no representan una realidad objetiva, externa. Las pautas que imponemos o adoptamos de otros no tienen por qué ser sofisticadas, pero sin una pauta nos quedamos sin pistas y no podemos comprender desde el lado de la recepción unas unidades de información que se muestran claramente aleatorias, carentes de rima o sentido. (Freeden, 2013: 22).

La relación de poder entre los dos polos de la comunicación, entre el proveedor del servicio y el usuario por una parte y el intérprete por otra, tiene su explicación 
en los factores ideológicos y percepciones que tienen unos de otros. Las actitudes y creencias, tanto personales como de masas, no son ajenas al proceso de intercambio de información en general, pero cobran unas dimensiones determinantes en los Servicios Públicos porque estamos tratando del Otro y con él, con una serie de actitudes que oscilan entre el paternalismo excesivo y el rechazo más categórico, aunque sin perder, la mayoría de las veces, los formalismos administrativos.

Estas interferencias afectan, por supuesto, a la manera en que se procesa, se recibe y se reacciona ante el concepto de pudor o lo que pueda considerarse como tabú. Se observan las implicaciones ideológicas igualmente en la asunción de algunas convicciones que pueden torpedear la comunicación; el hecho de relacionar el pudor-tabú tanto desde el paternalismo como desde el rechazo, arriba mencionados, con una realidad sobrepasada por el Yo o por una supuesta inmadurez cultural. De hecho, el tema del sexo y sus derivados semióticos no se aprecia ni valora del mismo modo entre España y las distintas culturas árabes. En el mundo árabe se tiene el tópico de que los occidentales tienen un serio problema "cultural" con el sexo y su asimilación, y que han pasado de su negación histórica como algo nefasto y nefando a su explicitación excesiva en el espacio público.

Los árabes, en cambio, lo entienden como algo personal, íntimo, del cual se puede hablar públicamente (en espacio íntimos) entre iguales. De hecho, muchas occidentales se escandalizan cuando, en reuniones femeninas con mujeres árabes, se les pregunta qué medios anticonceptivos usan o la frecuencia de sus relaciones sexuales. De estas dos apreciaciones, árabe y occidental, se puede inferir que el problema no es la afirmación o negación del sexo, sino cómo se conceptualiza y con quién se puede hablar de él. Si una occidental se escandaliza cuando una árabe -"que no conoce de nada" o "que apenas conoce"- le habla de la frecuencia de sus relaciones íntimas, una árabe tampoco admite que se hable de este mismo tema si no es entre iguales.

Esta normalización del tema del sexo es la que muchas veces complica la comunicación. El tema del sexo no es, por tanto, una cuestión de conservadurismo-progresismo, de derechas-izquierdas, de desarrollo-atraso (en este caso concreto), sino de distintas percepciones y normalizaciones del tema. En muchas de las culturas árabes, el sexo se percibe como una necesidad biológica -aunque placentera- como lo podría ser comer o, incluso en ocasiones, deponer. De hecho, en la genuina cultura árabe tampoco se exhibe lo que uno come o deja de comer en su casa o la frecuencia de sus idas y venidas al baño. Esta comparación puede sorprender o incluso escandalizar, pero así es como se percibe y conceptualiza el sexo. De hecho, expresiones mecánicas como "ir a cambiar el aceite", "vaciar el aceite", "recargar las baterías"; la expresión francesa "faire le vidonge"; expresiones biológicas como "saciar a la amada o al amado"; o incluso legales como "ir uno a cumplir con sus obligaciones", hacen referencia al sexo. El sexo en general es metaforizado en la cultura árabe, explicitarlo demasiado arroja al hablante al ámbito social del hampa, de las clases más bajas de la sociedad. De hecho, proferir expresiones sexuales explícitas -fuera del ámbito demasiado íntimo y morboso- solo se le oye en la calle a los alcohólicos, drogadictos o personas con necesidades mentales específicas. 
Incluso en estos círculos más íntimos, cuando se habla explícitamente de ello, mencionando el aparato sexual y las distintas formas de practicar el sexo, casi nunca se refiere uno a una pareja estable querida, sino a una relación demasiado esporádica, al sexo de la calle o a la prostitución. Cuando una persona árabe habla explícitamente de ello, se sitúa a sí misma o sitúa a su pareja -desde sus patrones culturales, además de lo que se ha dicho anteriormente- en una categoría inferior.

El proveedor español del servicio diría que esta persona no tiene cultura sexual y que "es como Nosotros hace cincuenta años" (o los que sean); un árabe, a su vez, colocaría a su interlocutor en la categoría de reprimido o incluso barriobajero, que para sentirse realizado tiene que hablar de sexo. De hecho, abundan otros tópicos, esta vez de árabes hacia occidentales en general:

- "Se limitan a los orgasmos verbales".

- "Mucha lengua, y hasta la utilizan para todo".

- "Mucho hablan, poco hacen".

- "A ellos la teoría, a nosotros la práctica".

- "Para estar lamiendo todo el rato, mejor un cachorro, así se ahorra una lavar calzoncillos y planchar camisas".

- "Son bimotores: uno, cintura para arriba, y otro inoperativo, cintura para abajo".

- "Pasan besándose todo el día y no pasan de ahí".

- "El que haya demasiado desnudo en la calle y en el arte es un problema. La realidad vivida no se puede mitificar. No hace falta pintar un desnudo para verlo".

- "Cuando una occidental te dice que va a vestirse para salir significa que se va a desvestir. Debía ser al revés: la bata para la calle, o el chándal para la calle, y lo ligerito para casa".

El tópico, por tanto, no es solo de la mayoría hacia la minoría, sino también al revés. Las implicaciones ideológicas empiezan desde el momento en que el proveedor del servicio-usuario asume la voz colectiva, Nosotros, designando a su interlocutor como Vosotros, o incluso como Ellos (cuando se dirige al intérprete): "Ellos", "o es que ellos"... Aun más, el mismo intérprete forma parte a veces del Vosotros en el discurso del proveedor del servicio; es decir, que este engloba tanto al cliente del servicio como al intérprete, miembro del exogrupo, en este Vosotros colectivo: "Es que vosotros"... Así, cuando uno de los dos polos pluraliza el sujeto hablante o el receptor, la comunicación se vuelve complicada; especialmente cuando hace referencia a aquello que se supone íntimo, la comunicación se hace difícil.

\section{Conclusión}

El tema del tabú, como consecuencia del rubor, en la interpretación en los Servicios Públicos es un tema determinante para la fluidez de la comunicación y la eficiencia en la trasmisión de las ideas. La descripción del porqué de este fenómeno y sus alcances culturales e ideológicos puede arrojar un poco de luz sobre este tema. Cabe recordar que la eficiencia comunicativa y la articulación del discurso no des- 
cansan exclusivamente sobre el dominio de los formalismos lingüísticos, sino que responden a una serie de condicionamientos de tipo social y cultural.

Es evidente que la representación de las relaciones de pareja es distinta en las culturas árabes y española. Fuera de la pareja propiamente dicha, el discurso sobre el sexo y la pareja es poco explícito. Estas prácticas lingüísticas se presentan como poco explícitas en espacios o con personas que se juzgan ajenas al espacio íntimo. Por eso crea cierto malestar comunicativo cuando el discurso se explicita fuera del espacio íntimo.

Este discurso se naturaliza, sin embargo, entre iguales del mismo sexo. En estos contextos, el discurso sobre el sexo no presenta ninguna característica morbosa ni puede juzgarse como poco natural; es explícito. Es implícito y metaforizado cuando hay diferencias generacionales de edad o de sexo. En este sentido, se evita hablar de temas relacionados con la intimidad con personas de diferentes sexos o edad, a menos que sea una clase de educación sexual o de reproducción. En este caso, se imparte la instrucción de mayor a menor, pero idealmente con una persona del mismo sexo. En el caso del sexo femenino, a partir de la adolescencia, las jóvenes hablan abiertamente -con morbo o sin él- del tema de los embarazos, partes íntimas, enfermedades y malformaciones genéticas con sus madres o parientes femeninas más cercanas.

En todos los casos, tres factores son determinantes en las producciones lingüísticas sobre el sexo: el espacio, el tiempo y el género. Es frecuente oír entre árabes expresiones del tipo: "no es el lugar para hablar de esto", "ahora no podemos hablar de esto", "todavía es pronto para hablar de esto". En la interpretación en los Servicios Públicos, no tener en cuenta estos factores puede despojar a muchas conceptualizaciones abstractas de todas las valencias que las definen. Y lo es más cuando se trata de las diferencias entre el espacio público y el privado. Las diferencias entre ambos son culturales. En España, el espacio privado es reducido y casi transparente. Este, sin embargo, es amplio y opaco en el mundo árabe. Cualquier transgresión en este sentido se considera como irrupción en lo que es privativo. Del mismo modo, en España, las fronteras -vistas desde ojos árabes- entre el espacio público y el privado son borrosas. Sin embargo, en las culturas árabes, el espacio público, igual que el privado, es inviolable. Este se considera como un espacio de todos y debe consagrarse como un espacio neutral. El sexo, en este sentido, es parte de lo privado y no de lo colectivo. La transparencia amorosa y sexual publicitada en occidente es ajena a muchas culturas orientales, entre ellas la árabe. Es verdad que podemos observar amoríos callejeros también en el mundo árabe, pero esto es debido a la occidentalización y globalización cultural y moral paulatina de gran parte del universo. Este hecho también tiene su reflejo en la interpretación del rubor en los Servicios Públicos: no hay una pauta que pueda servir a todos por igual, pues podemos encontrarnos, aunque minoritariamente, con personas que hablen abiertamente del sexo, especialmente los varones; pero esta es la excepción y no la regla general.

\section{Referencias bibliográficas}

ANÓMINO: «Glittering prospects in the Emirates», Airberlin Magazin (diciembre 2013). CERCAS, J.: «El arte de la entrevista», El País - Semanal 1374, 8. (26 de enero de 2003). 
Consellis, A.: Public Service Interpreting. First Steps. Sydney: Palgrave Macmillan 2008, 128-142.

DE EPAlZA, M. (ed.): Traducir del árabe. Barcelona: Gedisa 2004.

El-MadKouri, M. / SOTO ARANDA, B. (2012): «Aspectos lingüísticos y extralingüísticos de la traducción jurídico-administrativa de documentos africanos en francés», Synergies Espagne 5 (2012), 111-128.

EL-MADKOURI, M.: «Lengua oral y lengua escrita en la traducción e interpretación en los Servicios Públicos», 2008, en http://www.tonosdigital.com/ojs/index.php/tonos/ article/view/183/143.

EL-MADKOURI, M.: «Lengua y Cultura en la traducción de la terminología jurídica árabe (el caso del estatuto personal)», Revista del Instituto Egipcio de Estudios Islámicos XXXIX (2012). Madrid: Instituto Egipcio de Estudios Islámicos.

El-Madkouri, M.: Lengua y cultura en la traducción de la terminología jurídica árabe (el caso del Estatuto Personal). (en prensa).

FreEDEn, M.: Ideología: Una breve introducción. Trad. de Javier Fernández Sebastián. Santander: Ediciones de la Universidad de Cantabri (2013).

ÍÑíGUEZ RUEDA, L.: El análisis del discurso en las ciencias sociales: variedades, tradiciones y práctica. Barcelona: UOC 2009.

NiDA, E. A. / TABER, CH. R.: La traducción: teoría y práctica. Madrid: Cristiandad 1974.

RichaRT, M. / RichART MARSET, M.: Ideología y traducción: por un análisis genético del doblaje. Madrid: Biblioteca Nueva 2012.

Torruella Valverde, J.: La adecuación en la interpretación en los SS. PP. Comunicación no verbal, temas «tabú»y reacción a ciertos rituales (Árabe-Español). Trabajo de Fin de Máster, Máster Universitario en Comunicación Intercultural, Interpretación y Traducción en los Servicios Públicos. Universidad de Alcalá de Henares 2013 (dirigido por Mohamed El-Madkouri).

VAlero Garcés, C.: Formas de mediación intercultural. Málaga: Comares 2008.

VAlero Garcés, C.: Traducción e Interpretación en los Servicios Públicos en el siglo XXI. Alcalá de Henares: Universidad de Alcalá de Henares 2011. 